\title{
Analysis of Colombia's Saber Pro results 2019 for natural science and environmental teachers training: Reflections and challenges in a higher education based in competences
}

\author{
César Augusto Aguirre León ${ }^{1}$, Elizabeth Moreno-Gómez ${ }^{1 *}$, Luis Juan Carlos García- \\ Noguera ${ }^{1}$ \\ ${ }^{1}$ Faculty of Education, Corporation University Minuto de Dios-UNIMINUTO, Bogotá, 11001000, \\ Bogotá/Colombia.
}

\begin{abstract}
University students from all academic programs and institutions of higher education in Colombia are evaluated through standardized tests that measure general and specific competencies according to the academic level (professional, technical). One of these tests corresponds to the called Saber Pro, where undergraduate students from all disciplinary areas are evaluated in two modules: generic (or basic) and specific competencies, which are related to evaluation, learning and teaching. The objective of this study is to carry out an analysis of the characterization of the population and the results that took the exam in 2019. The group correspond to teachers training in academic undergraduate programs in natural sciences and environmental education. The methodology carried out was the documentary analysis of the databases where we can find the results of this test for the study of population, the analysis of the results was carried out by qualitative and quantitative approach. Seventeen universities in the country of official and private origin were found with distance and face-toface modalities; characteristics of those evaluated students were established and there was also an analysis based on the individual averages per university for the test components. The analysis of the results allowed identifying the characteristics of socio-demographics, all most of them are in vulnerable situations, the women have major access to internet and computer tools and the educational levels completed is major in the students' mother. As for the module of generic and specific competences, the highest and lowest individual weights per university and gender were identified.
\end{abstract}

\section{Introduction}

During the self-evaluation processes of university students in Colombia, it was found a need to train in competencies that focus their learning processes for the development of skills that they will use in a given work and social context. These skills or competencies are

\footnotetext{
* Corresponding author: elizabeth.moreno.g@uniminuto.edu
} 
evaluated in higher education institutions' university students through annual tests called Saber Pro test. These tests are applied to evaluate processes and manage changes in response to contextualized problems [1]. The purpose of this test is to check the degree of development of the students' competencies, produce value-added indicators, and serve as a source of information for the construction of indicators for the evaluation of the quality of higher education programs and institutions [2].

These competencies were established by the Ministry of National Education in Colombia (MinEducación) and have a fundamental purpose, training in future teachers; they can be considered a set of capacities that can be measured in terms of knowledge, skills, and abilities [3]. The proficiency tests are organized to be taken in two blocks: the first corresponds to generic competencies, this includes critical reading, quantitative reasoning, citizenship competencies, written communication, and English; and, in the second block, we can find the specific competencies according to the academic program that the university student is studying [4]. It corresponds to teaching, training, and evaluation for teachers in training in all disciplinary areas [5].

As for the results obtained in these tests which have been analyzed. A study found a project which examines the competencies in teacher training of multidisciplinary (natural sciences and environmental education) and disciplinary (related to basic sciences) degrees; this study [6] determined the factors associated with performance in this test with the generic competencies of the students who belong to these academic programs.

The meaning of science teacher training in a culture of scientific and social research implies the linkage of the academic, labor, and research component that allows the preparation, motivation, and elaboration of projects based on a social and disciplinary sense. For this reason, it is proposed as a fundamental pillar that:

"The initial scientific-research training is essential since it allows the future professional to problematize, investigate, reflect on the educational reality and achieve transformations both in the context of action and on an individual level. Through the scientific-research activity, the student appropriates the scientific method through the acquisition of knowledge, the development of habits and research skills that allow him/her to use knowledge in theory and practice in a creative way to provide solutions, through scientific means, the problems he/she faces" [7].

In the case of specific competencies for teachers in training, focused on the natural sciences, [8] establishes that these should be: 1) to develop scientific thinking about real and contextualized worlds through language, to understand and construct theories, predict and control phenomena, etc., 2) to build the capacity to work as a team to consolidate and understand other ways of seeing the world, and 3) to create an interest in scientific knowledge related to developing sensitivity and understanding research problems. Consistently, [9] mention that training in competencies is associated with research and the stages of the research process, in which, they name a few examples, they refer to interpersonal relations of the process, management and administration of resources, leadership, socialization, interdisciplinarity, process evaluation, etc.

Training based on these scientific and research activities can be presented through the creation and participation of research incubators from teacher training. For the replication of scientific competencies with social impact, after undergraduate students acquire them, they will be replicated for primary or secondary students. A mechanism for training these skills is the creation of workshops in research, such as the work created by [10] students, graduates, and graduates in natural sciences from various universities in Chile; in this research, the methodology was proposed to develop a scientific research work for its subsequent dissemination and socialization. Likewise, the creation of extracurricular spaces related to research was found, which allowed for the autonomous generation of knowledge, 
creation and development of pedagogical experiences, and articulation with the dynamics of educational research [11].

\subsection{Problem and Aims of the research}

In different studies, the need for a training of the research teacher has been raised, since it turns out to be a determining factor of the quality of education since it allows to foster the search of knowledge, the development of scientific thought, the use of pedagogic, didactic, natural sciences and environmental education knowledge among others which correspond to the scientific-research skills. Similarly, it is important to highlight that the initial training that teachers receive is a factor, on the other hand, the success of the teacher depends on this with the implementation of didactic and pedagogical studies for the generation of scientific-research skills in the classroom for the area of natural sciences and environmental education. And, secondly, because the country needs the configuration of a system to create research incubators that promote the preparation of young people for science, technology and innovation, who are capable of recognizing and intervening in the different areas of Colombian society; in other words, if a country wants to guarantee significant growth in science, technology and innovation it must start from the premise that a good base could be its teachers in training. There has not been any conducted study on the characterization of the results of the pro-2019 knowledge tests of graduates in natural sciences and environmental education with the relationship of the sociodemographic and institutional characteristics that lead to reflection on test performance so far. Thus, this research's main objective is to evaluate the characteristics of the population and the results of natural science and environmental education degree programs in Colombia that presented the Saber Pro 2019 test and what extent scientific and research competencies are included in the creation of this exam.

\section{Method}

This research is a mixed methodological perspective since it focuses on the analysis of the Saber Pro tests and their relation to the measurement of the students' scientific and research competencies of the natural sciences degree. For this purpose, an integration methodology was used, that is to say, it makes use of a qualitative and quantitative approach to analyze the information. This methodological design was selected because it is an effective way to deepen studies on education through the identification of problems, correlation of variables, and generation of hypotheses about the knowledge found during the development of the study [12]. In this way, it is expected that the analysis will be known, and those proposals or strategies of action will be generated to strengthen the competencies of the study proposed here.

\subsection{Instruments for collecting information}

To identify, deepen and analyze the information, it was also possible to collect a background documentary [13] that would allow us to know about the public education policies that underlying the Saber Pro exam for undergraduate students in the country and national statistical results for 2019. Based on the preliminary review, categories of importance for the study and their respective source of information for document analysis were established. Table 1 illustrates this information and will guide the process of data collection for subsequent analysis.

Table 1. Documentary review. 


\begin{tabular}{ccc}
\hline Source & Institutions & Documents \\
\hline Test Saber Pro & $\begin{array}{c}\text { Instituto Colombiano para la evualuación de } \\
\text { la educación (ICFES) }\end{array}$ & $\begin{array}{c}\text { Legislative texts } \\
\text { concerning generic and } \\
\text { specific tests }[14,15,16]\end{array}$ \\
\hline National statistics & $\begin{array}{c}\text { Instituto Colombiano para la evualuación de } \\
\text { la educación (ICFES) }\end{array}$ & $\begin{array}{c}\text { Database available in } \\
\text { (version 13/04/2020) }\end{array}$ \\
\hline
\end{tabular}

Source: Compiled by authors

The qualitative procedure was carried out through analysis documentary analysis to interpret and track the category of analysis scientific and research competencies from the perspective of the creators of the Saber Pro tests. With regard to the quantitative method; to find the individual averages of the results by the university with their respective standard deviation, the analysis of the student data and results from the Saber Pro 2019 tests of the generic and specific components for the degree in natural sciences and environmental education consolidated in an Excel spreadsheet was used as a support and accessible analysis tool, which is easy to use and sufficient for the calculations.

\subsection{Population and sample}

In the collection of documentary information, the documents and data selected for the study are thoroughly investigated and analyzed. The sample includes the results of the Saber Pro 2019 tests of educational institutions nationwide. From there, it is possible to obtain the students' information through the electronic test registration form and the test results of the generic and specific components for degrees with denomination in natural sciences and environmental education [17]. The database is available at ftp.icfes.gov.co (version 01/07/2020).

\section{Results and discussion}

From the results of the databases, these were selected and organized by the universities that offer academic programs related to the degree in natural sciences and environmental education, and from this, the information in Table 2 was consolidated.

Table 2. General characterization of universities with this academic program.

\begin{tabular}{|c|c|c|c|}
\hline University & Type & Departamet & Institution \\
\hline Universidad De Córdoba - Montería & Online & Córdoba & Public \\
\hline Universidad Del Tolima - Ibagué & Online & Tolima & Public \\
\hline Universidad Popular Del Cesar-Valledupar & On-site & Cesar & Public \\
\hline Universidad De Nariño-Pasto & On-site & Nariño & Public \\
\hline $\begin{array}{c}\text { Corporación Universitaria Del Caribe - Cesar- } \\
\text { Sincelejo }\end{array}$ & Online & Sucre & Private \\
\hline Universidad Surcolombiana - Neiva & On-site & Huila & Public \\
\hline Universidad Del Valle - Cali & On-site & Valle & Public \\
\hline $\begin{array}{c}\text { Universidad Pedagógica y Tecnológica De } \\
\text { Colombia -Tunja }\end{array}$ & On-site & Boyacá & Public \\
\hline Universidad De Antioquia - Medellín & On-site & Antioquia & Public \\
\hline
\end{tabular}




\begin{tabular}{|c|c|c|c|}
\hline Universidad Del Cauca - Popayán & On-site & Causa & Public \\
\hline $\begin{array}{c}\text { Corporación Universitaria Minuto De Dios - } \\
\text { Uniminuto }\end{array}$ & Online & Bogotá & Private \\
\hline $\begin{array}{c}\text { Universidad Industrial De Santander- } \\
\text { Bucaramanga }\end{array}$ & On-site & Santander & Public \\
\hline $\begin{array}{c}\text { Universidad Tecnológica Del Choco "Diego } \\
\text { Luis Córdoba" - Quibdó }\end{array}$ & On-site & Choco & Public \\
\hline Universidad Santiago De Cali-Cali & On-site & Valle & Private \\
\hline Universidad Libre-Socorro & On-site & Santander & Private \\
\hline Universidad ICESI - Cali & On-site & Valle & Private \\
\hline $\begin{array}{c}\text { Universidad Del Magdalena - Unimagdalena } \\
\text { - Santa Marta }\end{array}$ & Online & Magdalena & Public \\
\hline
\end{tabular}

Source: Compiled by authors

From the consolidated results, it can be established that the universities with the highest demand for enrollment for this academic program are those which offer a virtual modality. The number of students who took the exam for the second cohort in 2019 was a total of 879 students; $71.3 \%$ were women and $28.7 \%$ men, in both cases the average age was between 22 and 32 years old.

The location of the socioeconomic stratum in Colombia is 1 to 6 and it's determined by characteristics of housing and location, in which 1 is the lowest level (vulnerable) to 6 which has special and privileged conditions within the economic system. The largest number of male and female students are found in levels 1 and 2,56.4\% for women and men $22.4 \%$. On the other hand, the lowest percentage of students in this program was found in higher socioeconomic strata (5 and 6 ) with $0.8 \%$ of women and $0.5 \%$ of men.

The results of the educational level for parents of natural science undergraduate students for this was the following, the percentage of a complete education, whether primary, secondary, postgraduate, or technological is higher for the mother at $46.4 \%$, while for the mother it is $38.3 \%$. In the different levels of incomplete or not completed education in any of the modalities already mentioned, we find that the highest percentage is for the fathers with $43.7 \%$ and for the mothers with $43 \%$.

As for the results of access to the internet and computer. It is found that women have a higher percentage of access to these tools with $41.4 \%$ having access to the internet and $47.8 \%$ having a computer. In contrast, male students have less access to technological resources with the following percentage: if they have access to the Internet with $15.4 \%$ and likewise have a computer with $18.8 \%$.

Finally, the results of the semester in which people are at the time of taking the tests. The information found shows that the highest percentage of students is in the ninth semester with $39 \%$ (women) and 36\% (men).

\subsection{Student Performance by Gender on Saber Pro Tests}

The results in quantitative reasoning skills, critical reading, citizenship skills, English, written communication, and an overall score for the female population that belongs to a natural science degree program. Were analyzed 17 universities (Table 2) which can be found in all the charts with their main names. The University of Magdalena in Santa Marta and the Instituto Colombiano de Estudios Superiores de Incolda University (ICESI) in Cali for the period of presentation of this test only had the result of one student, therefore their results did not have the representation of a standard deviation of the data. 
Figure 1 shows the results for female students, where the universities were organized in descending order according to the result of the global average of the competitions evaluated. The first module evaluated was that of quantitative reasoning, in which it was found that the average of the individual results, the highest score was for the university of Antioquia in Medellín with 149 points and in contrast the most achieved level was for the university of Magdalena with 98 points. For the critical reading module, citizenship skills and English, the highest score was obtained by the ICESI University in Cali with 170, 165 and 179 points. In particular, the lowest score was for Tecnológica Del Choco University "Diego Luis Córdoba" in Quibdó for these same modules with 115, 107, and 117 points respectively. Finally, the written communication module was considerably higher than the other universities with 175 points for the University of Magdalena, and with the lowest average individual results a value of 125 points for the Corporación Universitaria del Caribe in Cesar.

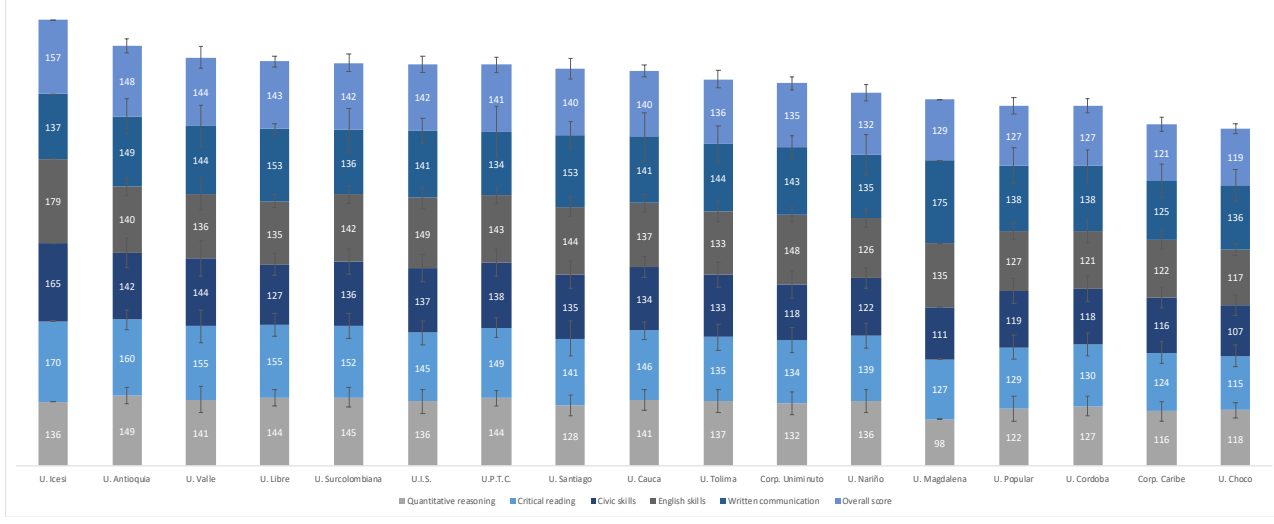

Fig. 1. Results of generic competencies in women.

Source: Compiled by authors

Similarly, Figure 2 shows the results in quantitative reasoning skills, critical reading, citizenship skills, English, written communication and overall score for the male population belonging to the bachelor's program in natural sciences. In this case, the university with the highest overall score was the Universidad Libre in Socorro (Santander) with 164 points for a single student taking the test for this period. In the quantitative reasoning and written communication module, this university also obtained the highest results with 189 and 182 points, respectively. For the critical reading and English module, the highest result was for the University of Antioquia in Medellín with 168 and 163 points, respectively. Finally, the Pedagógica y Tecnológica University of Colombia in Tunja had the highest result for the module of citizen competences with an average of individual results of 155 points

In contrast, the lowest average result was for Universidad Tecnológica Del Choco "Diego Luis Cordoba" in Quibdó with 116 points, where the modules of quantitative reasoning, English and written communication were the main affected with 113, 117 and 118 , respectively. The same occurs with the University Corporation del Caribe in Sincelejo where the lowest scores at the national level were for critical reading skills and citizenship skills with 115 and 106 points, respectively. 


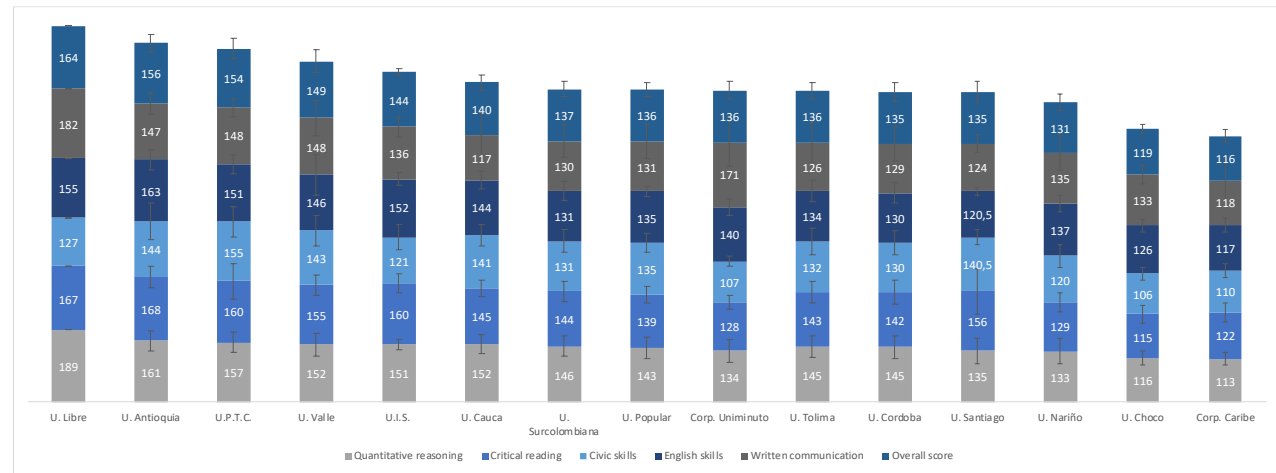

Fig. 2. Results of generic competencies in men.

Source: Compiled by authors

Figure 3 shows the modules evaluated for graduates that correspond to the competencies of teaching, evaluation, and training. This figure only shows the averages of the individual results for female students. The highest score for the three competencies evaluated was obtained by ICESI University of Cali $(n=1)$ with the following scores: teaching (200 points), evaluation (187 points), and training (182 points). Similarly, the University of Valle in Cali $(n=34)$ had outstanding scores of 174,179 , and 156 points, respectively.

The lowest scores were for the University of Magdalena in Santa Marta $(n=1)$, where the scores were 122, 103, and 120 in the above-mentioned competitions. It is considered that the number of people evaluated is a limiting factor of comparison, therefore it is evidenced that Technological University of Choco "Diego Luis Córdoba" in Quibdó ( $n=22)$ ; this population had very similar results with 123 points (teaching competence), 132 points (evaluating competence) and 121 points (training competence).

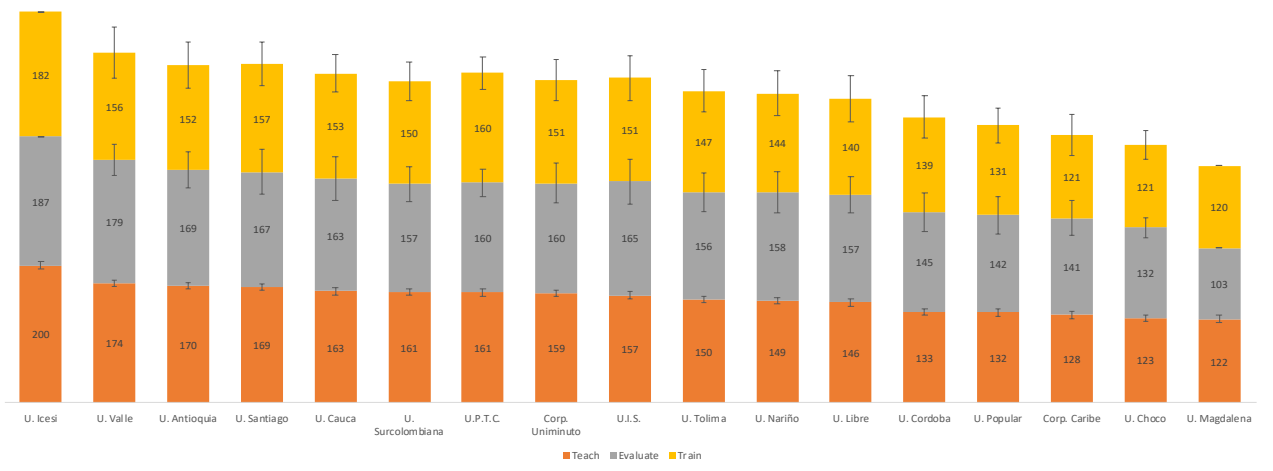

Fig. 3. Results of specific competencies in women.

Source: Compiled by authors

Figure 4 shows the results of the male students for the teaching, evaluation, and training competencies. From the results obtained, it is found that the highest average of individual results in the teaching-related competition is found in the University of Valle $(n=15)$ with a score of 176. In the second competition, evaluating the University of Santiago de Cali had the highest results with 173 points. And, in the case of the training module, they were for the universities Libre $(n=1)$ and Cauca $(n=16)$ with scores of 165 and 163, respectively. In 
the case of the scores for evaluating (123), forming (114) and teaching (117) obtained from the Universidad del Choco "Diego Luis Córdoba" was the lowest.

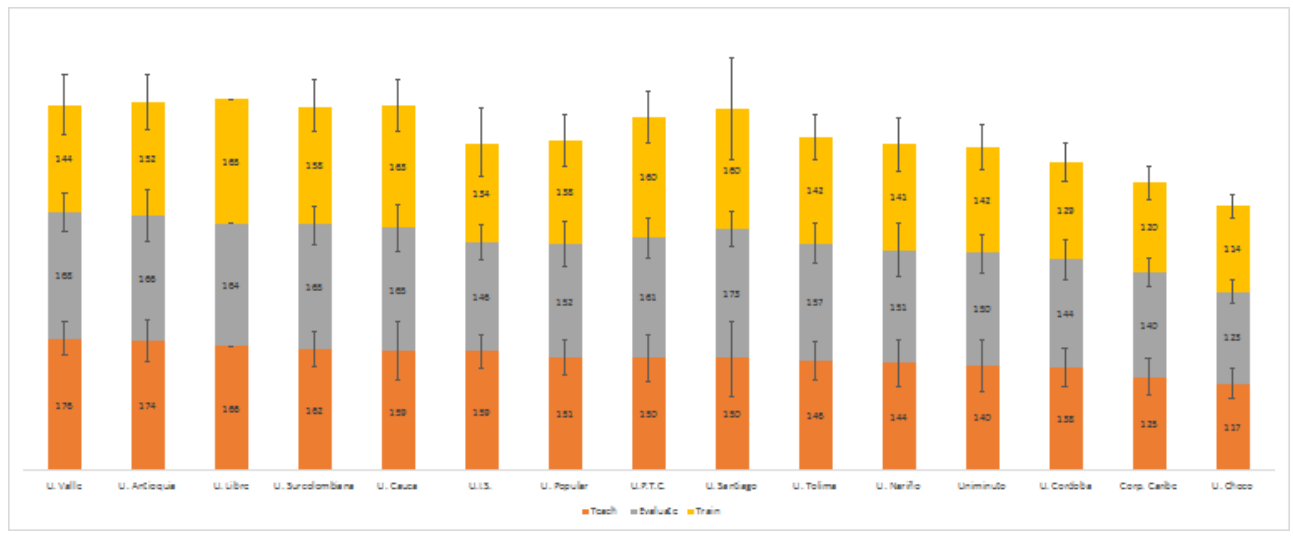

Fig. 4. Results of specific competencies in men.

Source: Compiled by authors

As for the level of achievement in the results of the competencies that these tests evaluate, it corresponds to a numerical meter of quality of higher education institutions about their future graduates. However, in relation to the skills that teachers must have in these areas, the question is more complex. One of them is scientific and research skills. These skills result from integrating knowledge (social, pedagogical and/or disciplinary), relating it to methodological procedures of research that leads to reflection, critical perspective, and analysis [18]. Providing opportunities to students for the generation of this knowledge-based on scientific and research competencies will allow teachers' training in natural sciences and environmental education that seeks to understand and transform realities in the teaching practice, in the curriculum, in the didactics under a real context.

\section{Conclusions}

With the analysis of the results of the Saber Pro 2019 tests in students of natural sciences and environmental education in the country, it can be inferred that from the totality of the students evaluated $(\mathrm{n}=879)$, in all the programs offered, there is a greater amount of female population with $71.33 \%$ students and male population with $28.67 \%$ students. In relation to the socioeconomic stratum in which they are found, both men and women belong to the lowest strata ( 1 and 2). With regard to the educational level of the student's family, it is possible to establish that the mother most frequently has the achievement of a completed academic degree, whether primary, secondary, technological, undergraduate or graduate, with $46.4 \%$; with regard to incomplete education, the fathers have a greater percentage with $43.7 \%$ and for the mothers $41 \%$.

In terms of technological tools, it was found that women in the study program have greater access to the Internet and computers with $58.1 \%$ and $67 \%$, respectively. In the case of the male population, there is less possibility of access to the technological tools mentioned above with $53.6 \%$ and $65.5 \%$. However, it should be noted that for both populations, the greatest obstacle is to have internet with an average of $38.6 \%$ and a computer with $27.6 \%$. The greatest amount of population evaluated in the exam is in the ninth and tenth semester with 59\% for women and 56\% for men. Similarly, those evaluated who take the exam in higher semesters are approximately the same with $37 \%$ and $35 \%$. 
As for the universities offering such programs, a total of 17 institutions were found, twelve of them are official (9 presential-4 Distance), and 5 are private (3 presential-2 Distance). The university with the highest demand for students is the University of Cordoba with 148 students; in addition, in all cases there are more female students.

Although different studies exist where they manage to establish that the gender is not a factor that has a relationship with performance in these specific modules [19] the results are presented with this organization since it is necessary to know specific problems based on this characteristic in the results of the generic competencies of quantitative reasoning, critical reading, citizenship competencies, English and written communication for the female population, it was found that the highest global score of the individual averages was for the University of Antioquia and with the lowest score resulting from the individuals, was the Technological University of Chocó. In the case of the male population, the Libre University stood out for the highest overall average score and the Caribe Corporation for the lowest score. In the specific competencies, it was found that the highest individual scores were for women in the ICESI University and the University of Valle with all three competencies, and in the case of men, in the teaching competency the highest weight was obtained in the University of Valle, in the competencies related to evaluating and training the highest averages were for University of Santiago de Cali.

The studies established for this academic program as a factor of positive performance in students of an institutional nature, for example, the accreditation of the academic program, since implicitly this factor establishes curricular plans of action, reflection and research through strategies or teaching models that allow the development of scientific thinking competences through their explanation and understanding of science [20].

These skills include the development of scientific thinking, the capacity for problematization, oral and written communication, the development of an analysis, capacity for synthesis and abstraction, etc. [21], which in the first place aim for teacher training with integration of research practice, knowledge in science and environmental education with the problems and contextualized solutions, all of which imply the development of all the skills evaluated by the MinEducación. The Saber Pro 2019 tests conducted in Colombia for teachers in natural science and environmental education training evaluate specific competencies related to training, teaching, and evaluation, in which in some cases scientific and research skills are considered.

Therefore, to strengthen the results of these tests, I believe it is necessary to provide spaces where these students can develop experiences that enrich their training and apply disciplinary, pedagogical and didactic knowledge, with a focus on intervention in a real context. This is how the generation of a culture of science and research in teacher training could be configured to positively impact teachers and students of these academic programs.

For this reason, and to contextualize this approach, we ask, as a reflection, what would be the strategies that promote the generation of scientific research skills with the use of science for educational and social impact, how can scientific and research skills be strengthened in undergraduate students to contribute to solutions in the framework of a post-pandemic? What are the challenges in accessing competency-based education, how do research and science skills contribute to performance on proficiency test scores, and what would be the impact on teachers and students in these academic programs if training were focused on these strategies?

\section{Acknowledgements}

This study was part of the analysis of the project signed in the research contract with cofinancing number C120-59 in the University Corporation Minuto de Dios of Bogotá, principal campus. Likewise, it appreciates the data provided for the analyses of the Instituto 
Colombiano para la Evaluación de la Educación (ICFES). For the last time, I thank language editing to Professor Jaime Alejandro Viana Astaiza.

\section{References}

1. J. N. Velásquez, C. R. Rios, C. Y. Martínez and L. F. Mendoza, Conocimiento del contenido en formulación de preguntas de competencias específicas en la prueba Saber Pro para docentes en formación de ciencias naturales en Colombia, Rev Bio-grafía Escritos sobre la biología y su enseñanza, 10, 19 (2017) https://doi.org/10.17227/biografia.extra2017-7132

2. Icfes. Guia de orientación Saber Pro 2019. Módulo de Competencias Genéricas. Instituto Colombiano para la evaluación de la educación, MinEdcación (Colombia).

3. A. Castro and R. Ramírez, Docentes vs. estudiantes. Contradicciones en la enseñanza de las ciencias naturales para el desarrollo de competencias científicas, Rev Interamericana de Investigación, Educación y Pedagogía, 5, 1 (2012) https://doi.org/10.15332/s1657-107X.2012.0001.02

4. Icfes, Orientaciones para el examen de Estado de calidad de la educación superior SABER PRO (ECAES), Prueba de competencias comunes en área de educación. Bogotá, Colombia (2011).

5. Ministerio de Educación Nacional (MinEducación), Lineamientos de Calidad de las Licenciaturas en Educación, Bogotá, Colombia (2014).

6. C. Y. Martinez Rodriguez and L. F. Mendoza Pinilla, Análisis de los resultados de la evaluación en competencias genéricas de las prueba SABER PRO 2014 en programas de Licenciatura en el área de las ciencias naturales y educación ambiental de cuatro universidades del País, Thesis degree, Bogotá (Colombia), Distrital Francisco José de Caldas University (2016)

7. D. González and G. Achiong, La labor tutorial y su impacto en la formación científicoinvestigativa inicial del docente, Rev Educacao e Pesquisa, 44, (2018) https://doi.org/10.1590/S1678-4634201844165094

8. H. Escobedo, Desarrollo de competen- cias básicas para pensar científicamente. Una propuesta didáctica para las ciencias naturales. Bogotá: Colciencias (2001).

9. D. Higuita-López, J. H. Molano-Velandia, and M. F. Rodríguez-Merchán, Competencias necesarias en los grupos de investigación de la Universidad nacional de colombia que generan desarrollos de base tecnológica, Rev Innovar, 21, 41 (2011)

10. C. A. Faúndez, A. A. Bravo, H. F. Astudillo and P. G. Salgado, Diseño de un Taller de Investigación en Micro-Didáctica-Física para la Formación de Profesores de Ciencias Naturales, Rev Formación Universitaria, 8, 5 (2015) https://doi.org/10.4067/s0718$\underline{50062015000500008}$

11. N. Dehesa de Gyves, La investigación en el aula en el proceso de formación docente, Rev Perfiles Educativos, 37 (2015)

12. J. Monteagudo Fernández and R. Facal López, Estándares de aprendizaje y evaluación del pensamiento histórico, ¿incompatibles?. Análisis de currículos, programaciones, exámenes y opinión de expertos en España, Rev Perfiles Educativos, 40, 161 (2018) https://doi.org/10.22201/iisue.24486167e.2018.161.58586

13. A. Carbonnel, D. Ruz, A. M. Osorio and C. Hernández, Modelo Pedagógico de educación cintífica escolar. Innovación social en localidades rurales, Rev Perfiles Educativos, 41, 166 (2019) https://doi.org/10.22201/iisue.24486167e.2019.166.59032

14. Icfes, Guia de orientación Saber Pro. Módulo de Enseñar. Instituto Colombiano para la evaluación de la educación, MinEdcación, Bogotá, Colombia (2019).

15. Icfes, Guia de orientación Saber Pro. Módulo de Evaluar. Instituto Colombiano para la evaluación de la educación, MinEdcación, Bogotá, Colombia (2019), 
16. Icfes, Guia de orientación Saber Pro. Módulo de Formar, Instituto Colombiano para la evaluación de la educación, MinEdcación, Bogotá, Colombia (2019)

17. F. A. Gil, V. A. Rodríguez, L. A. Sepúlveda, M. A. Rondón and C. Gómez-Restrepo, Impacto de las facultades de medicina y de los estudiantes sobre los resultados en la prueba nacional de calidad de la educación superior (SABER PRO), Rev Col de Anestesiología, 41, 3 (2013) https://doi.org/10.1016/j.rca.2013.04.003

18. J. Rodríguez-Sosa, S. K. Lingan, R. M. Hernández and J. Alhuay Quispe, Experiencia de innovación en el desarrollo profesional docente, Rev Interdisciplinaria, 34, 2 (2017)

19. C. R. Rios Avella and J. N. Velasquez Almonacid, Análisis sobre las competencias específicas en pruebas saber pro 2014 en programas de formación de licenciatura en biología, licenciatura en química, licenciautura en física y licenciatura en ciencias naturales y educación ambiental en cuatro (4) universidades del país, Thesis degree, Bogotá (Colombia), Distrital Francisco José de Caldas University (2017)

20. M. T. Torrente Díaz, W. A. Guevara, S. Echeverry Hernández and E. F. Amortegui Cadeño, Enseñanza de competencias de pensamiento científico por resolución de situaciones problematizadoras a futuros docentes de ciencias naturales, in Proceedings of VII Encuentro Nacional de Experiencias en la Enseñanza de la Biología y la Educación Ambiental and II Congreso Nacional de Investigación en la Enseñanza de la biología, 23-25 oct 2013, Bogotá, Colombia (2013)

21. C. Rojas Granada and S. Aguirre Cano, La formación investigativa en la educación superior en América Latina y el Caribe: una aproximación a su estado del arte, Rev Eleuthera, 12 (2015) https://doi.org/10.17151/eleu.2015.12.11 